Alma Mater Studiorum - Università di Bologna DEPARTMENT OF ECONOMICS

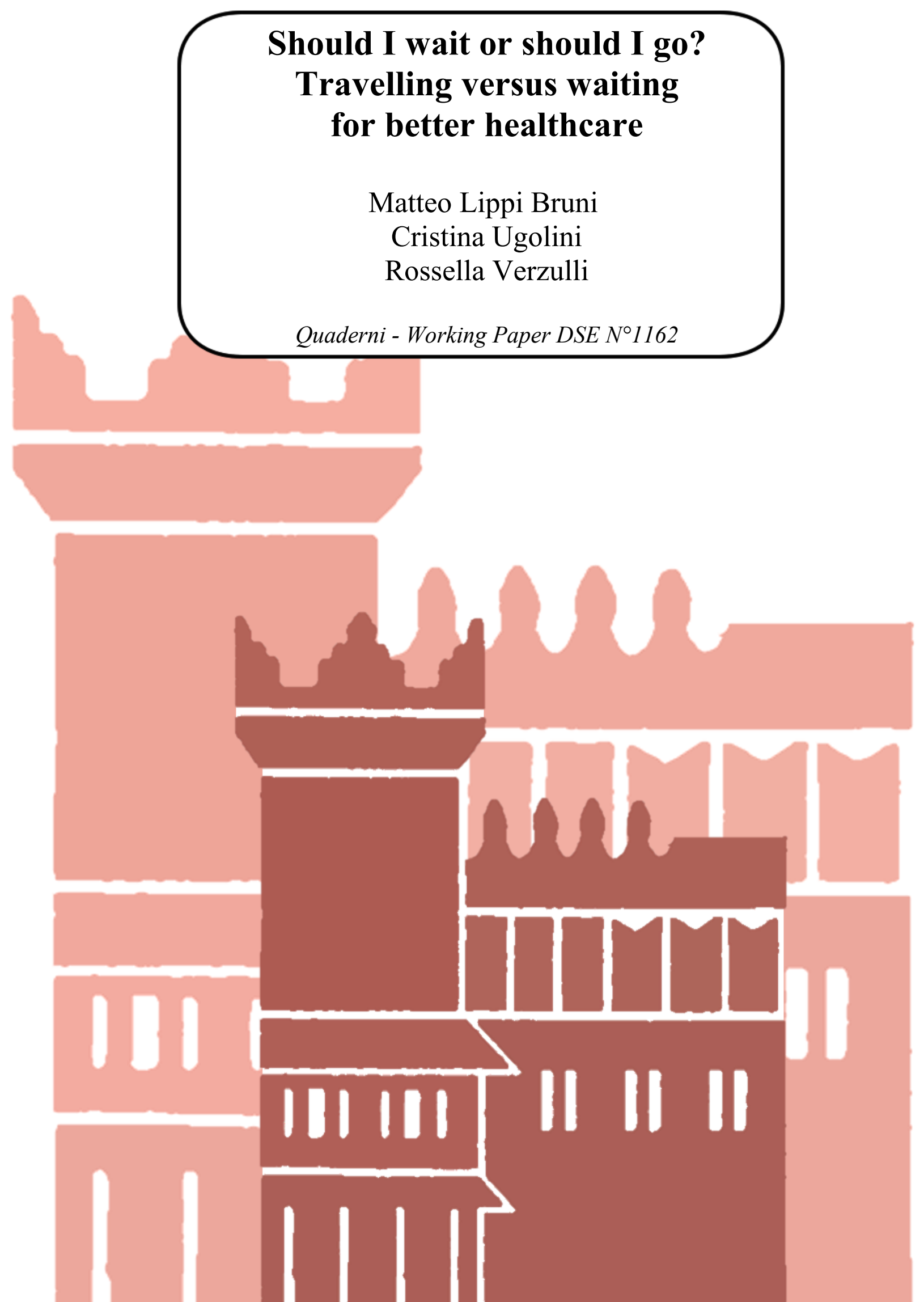




\title{
Should I wait or should I go? \\ Travelling versus waiting for better healthcare ${ }^{1}$
}

\author{
Matteo Lippi Bruni, Cristina Ugolini, Rossella Verzulli. \\ Department of Economics, University of Bologna, Italy. \\ matteo.lippibruni2@unibo.it; cristina.ugolini@unibo.it; rossella.verzulli@unibo.it
}

May 2021

\begin{abstract}
We study patient mobility in the Italian National Health System, using patient-episode level data on elective Percutaneous Transluminal Coronary Angioplasty procedures over the years 2008-2011. We examine how patients' choice of the hospital is affected by changes in waiting times and clinical quality within hospitals over time. We estimate mixed-logit specifications and show the importance of jointly controlling for timeinvariant and time varying clinical quality to identify the effect of waiting times. Conversely, failure to capture variations in clinical quality over time does not affect the estimate of the discouraging effect of travel distance. We provide evidence that patients are responsive to changes in waiting times and clinical quality: average demand elasticity with respect to own waiting times and mortality is estimated to be -0.17 and -1.38 , respectively. Patients' personal characteristics significantly influence how they trade off distance and waiting times with quality of care. We find a higher WillignessTo-Wait and Willingness-to-Travel to seek higher quality care for patients in the younger age groups and who are more severely ill. The results convey important policy implications for highly regulated healthcare markets.
\end{abstract}

Key words: patients' mobility; hospital choice; travel distance; waiting times; healthcare quality; mixed logit models.

JEL codes: I1 1, I18, R22

\footnotetext{
${ }^{1}$ This is a fully revised and updated version of the paper previously circulated under the title "Disentangling the effect of waiting times on hospital choice: Evidence from panel data", Quaderni Working Paper DSE, No. 1118, 2018, University of Bologna.
} 


\section{NON-TECHNICAL SUMMARY}

This paper investigates the determinants of patients' mobility in the healthcare sector. There is a growing interest in evaluating how patients' mobility responds to variations in waiting times and clinical quality, as this provides key insights for policy.

Considering patients' preferences for a highly relevant speciality in the field of cardiology (Percutaneous Transluminal Coronary Angioplasty procedures), we examine how geographical accessibility interacts with waiting times and clinical quality in affecting patients' choice of hospital for elective treatments. We estimate patient choice models by using data from the Emilia-Romagna region in Italy over the period 2008-2011. The institutional context we study is such that hospitals operate under weak competitive pressure, and evidence on how patients trade off aspects of health care quality under these circumstances is still lacking.

We find that waiting times have a negative and significant impact on hospital demand, with the estimated average elasticity of demand for waiting times being -0.17 . On average, patients are willing to travel an extra distance of about 1.4 kilometers for shortening waiting times for care by 1 week. We detect relatively little variation in the trade-off between waiting times and distance across different types of patients. Hospital choice is more significantly affected by changes in clinical quality, with the estimated average demand elasticity to mortality rates being -1.38 . Responsiveness to changes in hospital quality varies substantially across patient characteristics, with younger age groups and those more severely ill being more willing to trade off quality with distance and waiting times.

The results suggest that quality disclosure policies may have beneficial effects also in highly regulated settings. Yet, policy-makers should carefully consider the consequences in terms of access to high quality care for those patients who are less sensitive to quality variation. 


\section{Introduction}

Timely access to, and quality of, hospital services are central concerns for patients and regulators (e.g., Beckert et al, 2012; Gravelle et al, 2014; Gaynor et al, 2016; Gutacker et al, 2016). However, assessing the determinants of patient choice is challenging due to the multidimensional nature of quality and to the limited observability of important attributes. This notwithstanding, there is a growing interest in understanding how patients' mobility responds to variations in waiting times and clinical quality, as this offers key insights on patients' preferences.

Two waves of initiatives have boosted the relevance of these issues in public health systems: the enhancement of patient choice and the effort for shortening waiting times. Patient empowerment reflects the belief that greater choice can spur public organisations by promoting better quality and higher social welfare (e.g., Cookson and Dawson, 2012). Alongside with waiting times acting as a rationing device, long waits for care have become a major policy concern (Siciliani et al, 2014).

However, there are also reasons for scepticism about patients' ability to exercise an active choice when equity-oriented policies hinder competition, and common quality standards level out differences across providers, leaving patients with little incentive to bypass the nearest facility. Thus, it remains an empirical matter to determine whether patient choice is affected by preferences over factors other than geographical proximity, and to estimate the trade-off between hospital attributes (Balia et al, 2020).

We study patients' mobility in the Italian National Health Service (NHS) where secondary care is free of charge and patients' costs stem mainly from travel distance 
and waiting times. Hospitals retain incentives to attract patients, as they receive reimbursement through a Diagnosis Related Group (DRG)-based Prospective Payment System (PPS) (Lippi Bruni and Mammi, 2017; Cappellari et al, 2016). We analyse hospital choice in response to changes in waiting times and clinical quality within hospitals over time by using patient-level data on elective Percutaneous Transluminal Coronary Angioplasty (PTCA) for the period 2008-2011. Clinical quality is measured by mortality for Acute Myocardial Infarction (AMI), which is the key time-varying quality measure in our analysis (Berta et al, 2016; Moscelli et al, 2018).

We contribute to the literature on patient mobility and hospital choice by investigating the joint influence of hospital geographical accessibility, waiting times and clinical quality. Isolating the effect of distance and waiting times poses serious challenges because choice may reflect preferences for quality. If patients are sensitive to clinical quality, hospitals delivering better care will face higher demand, possibly inducing a positive correlation between waiting times and quality. Similarly, patients may be more or less discouraged by distance depending on perceived quality. Therefore, variations in hospital quality should be controlled for in order to obtain unbiased estimates of patients' Willingness-To-Wait (WTW) and Willingness-To-Travel (WTT).

We estimate conditional logit (CL) and mixed logit (ML) model specifications. We improve on existing studies on a number of issues. First, our estimation strategy jointly controls for time-invariant heterogeneity across providers via hospital fixed effects (FEs) and for time varying hospital quality. We show that failing to do so leads to biased estimates for the effect of waiting times. Conversely, in our study failure to account for variations in quality over time does not affect the estimate of the distance 
parameters. Notably, our findings lend support to the ML model, displaying preference heterogeneity for both unobserved and observed patient characteristics. Second, we investigate patients' preferences for a highly relevant speciality in the field of cardiology and in an institutional context where hospitals operate under weak competitive pressure, for which evidence on how patients trade off aspects of health care quality is still lacking. Third, we assess how the trade-off among hospital attributes vary with patients' characteristics. Detecting preference heterogeneity in terms of WTW and WTT for better quality and shorter waiting times is important for policy and helps target patients who are more at-risk of suffering from poor health care quality. Whereas some earlier studies looked at the trade-off between travel distance and hospital attributes such as waiting times and quality of care, to our knowledge we are the first to provide estimates of patients' WTW for higher quality. Policy makers may be interested in the extent to which longer waits may discourage patients from demanding higher quality care.

Our preferred specification yields an average elasticity of demand with respect to own waiting times of -0.17 , suggesting that a $1 \%$ increase in average waiting times $(0.16$ days) leads to a decline in the predicted number of admissions by around $0.17 \%$. With respect to own quality, the average elasticity of demand is equal to -1.38 , so that a $1 \%$ increase in mortality rate $(10 \%$ of the sample average) reduces demand by around $1.4 \%$. The marginal rate of substitution between hospital attributes provides further insights. On average, patients are willing to travel an extra distance of about 1.4 kilometers for a 1-week reduction in waiting times. We find relatively little variation in the trade-off between waiting times and distance among different types of patients, with the 
reference patient having a WTT for a 1-week reduction in waiting times equal to about 2 kilometers. By contrast, patients' sensitivity to quality varies largely across patient characteristics, with younger groups and those more severely ill being more willing to trade off quality with distance and waiting times.

\section{Background and motivation}

\subsection{Institutional setting}

The Italian NHS is funded out of general taxation and provides universal coverage. Secondary care is largely supplied by public hospitals, either run by Local Health Authorities (LHAs) or operating as public Trusts, with administrative autonomy, extensively paid under PPS. ${ }^{2}$ Primary care is organised as a list-based system and citizens are registered with a General Practitioner (GP). When referred by their GP or by a specialist, patients can access any publicly funded hospital. Since patients are not charged at the point of use, travel distance, waiting times and quality of care are the key drivers of hospital choice.

In the Italian NHS regions benefit from a large autonomy in organising and funding their health system (Di Novi et al, 2019). ${ }^{3}$ Regions like Lombardy have encouraged competition within the public sector, as well as between public and accredited private

\footnotetext{
${ }^{2}$ Accredited private hospitals generally play only a minor role (Fattore et al, 2013). In Emilia-Romagna acute care beds covered by accredited private hospitals amount to $12 \%$.

${ }^{3}$ Such feature has also induced the economic literature on the Italian NHS to concentrate on singleregion studies taking advantage of a homogenous institutional setting (e.g. Martini et al, 2014; AmaralGarcia et al, 2015; Lippi Bruni et al, 2016; Perucca et al, 2019, Barili et al, 2021).
} 
centres (Moscone et al, 2012). On the contrary, in Emilia-Romagna policy-makers have favoured cooperation and coordination among providers by centrally planning production capacity, and by promoting a strong integration between hospital- and district-level services (Ferré et al, 2014). Located in the North-East of Italy, with a population of nearly 4.5 million people, the healthcare system of Emilia-Romagna can be broadly compared in terms of size, standards of services and underlying socioeconomic conditions to the NHS-based systems of small and medium western European countries. Moreover, Emilia-Romagna is among the five Italian regions serving as benchmark to assess the health needs and the standard costs used to identify the basket of services covered by the NHS ("Essential Levels of Care"), giving national prominence to this regional context (Verzulli et al, 2017).

\subsection{Related literature}

Our work relates to two partially overlapping strands of literature: the studies on patient mobility and those that estimate demand elasticity to own waiting times. Hospital choice for elective care is inherently linked to patient mobility. ${ }^{4}$ Earlier works have studied the influence of patients' and providers' characteristics on the propensity to seek treatment at hospitals other than the closest one (e.g. Tai et al, 2004; Varkevisser and van der Geest, 2007; Robertson and Burge, 2011). Focusing on the Italian case, more recent contributions have investigated patients' migrations across jurisdictions by examining the push and pull factors and the financial consequences of patients seeking

\footnotetext{
${ }^{4}$ See Brekke et al (2014) for a review of the hospital choice literature, and Aggarwal et al (2017) for a survey on patient mobility.
} 
care out of their catchment area (e.g. Fabbri and Robone, 2010; Balia et al, 2014, 2018, 2020; Berta et al, 2021).

Hospital choice models typically rely on a multinomial logit specification, with patients choosing a provider within a set of possible destinations. The bulk of this literature uses cross-sectional data, and measures quality by means of clinical indicators such as mortality and readmission rates (Beckert et al, 2012; Varkevisser et al, 2012; Berta et al, 2016; McConnell et al, 2016). However, such variables may be correlated with unobserved hospital attributes affecting patient behaviour. By contrast, other contributions use a longitudinal design with hospital fixed effects, thus controlling for unobserved time-invariant heterogeneity across hospitals (e.g. Hodking, 1996; Tay, 2003; Gaynor et al, 2016; Gutacker et al, 2016; Moscelli et al, 2016; Avdic et al, 2019).

Demand response to waiting times has attracted considerable attention as well. A body of literature has used aggregate data at the ward and practice level (e.g. Martin and Smith, 2003; Gravelle et al, 2002), or has focused on small areas (e.g. Gravelle et al, 2003). Although with some variability, these studies have consistently outlined a negative and significant elasticity to waiting times, with estimates in most cases ranging between -0.2 and -0.3 . As for Italy, Riganti et al (2017) find a demand elasticity to waiting times for surgical treatments between -0.15 to -0.24 .

Even though individual-level information helps avoid the "ecological" fallacy when indicators capture effects that do not occur at the individual level (Martin and Smith, 1999), it has seldom been exploited to analyse the elasticity of demand for waiting times, as we do here. Moreover, patient-level data allows controlling for individual characteristics including hospital proximity, which improves estimate precision and 
makes it possible to analyse the trade-off between distance and waiting times (Pope, 2009). We account for preference heterogeneity for hospital characteristics, by interacting hospital attributes with patient characteristics and allowing preferences to vary randomly across patients.

\subsection{Our contribution}

The works closest to ours are Sivey (2012) and Moscelli et al (2016). The first uses patient-level panel data to study the impact of waiting times for cataract patients from English GP practices. It applies a multinomial logit framework and controls for quality differences via hospital FEs. The paper shows that, while waiting times positively affect choice before controlling for hospital time-invariant heterogeneity, the impact comes out negative once hospital FEs are included. The second contribution uses a panel of English hospitals to study how local market conditions - measured by the number of local rivals - affect demand elasticity for hip replacements, once quality of care, waiting times and distance are accounted for.

We differ from these contributions on a number of issues. First, we consider cardiovascular interventions where mortality rates are higher compared to cataract surgeries and hip replacements: a feature expected to affect WTT and WTW for higher quality of care. Second, identification in Sivey (2012) relies on the assumption that hospital quality does not vary over time, therefore excluding time-varying quality indicators: a restriction that is overcome in our context. In Moscelli et al (2016), the dynamics of the hospital market do not allow to control for unobserved characteristics at the level of single hospital, but only for homogeneous groups of providers. By 
contrast, we use a balanced sample of providers and include hospital FEs to account for time-invariant unobserved heterogeneity possibly associated with quality.

A further distinguishing feature of our work is the stability of the regulatory framework, which has always allowed free patient mobility (Levaggi and Zanola, 2004). This minimizes confounders due to providers' reactions to changes in the competitive environment. When patients are given greater choice opportunities, providers are incentivised to improve their attractiveness. Hence, when greater choice is introduced it may be hard to separate demand- from supply-side effects (Gaynor et al, 2016). Moreover, here providers are encouraged to co-operate rather than to compete, and the system is committed to ensure equity through regulated quality standards.

Finally, we assess how the trade-off among hospital attributes vary with patients' characteristics. Detecting preference heterogeneity in terms of WTT and WTW for better quality is important for policy, as it may help target patients who are more atrisk of suffering from poor quality services. While the former issue has attracted some attention, the latter has remained largely unexplored so far. Quite interestingly, we find a fairly steep gradient associated to changes both in severity conditions and patients' age. When the number of comorbidities increases, patients appear more willing to wait to gain access to a better performing centre, other things equal. On the contrary, ageing per se pushes patients in the opposite direction, with older individuals being more prone to obtain a quick access to treatment rather than to wait longer for being admitted in higher quality hospitals. 


\section{Methods}

We estimate responsiveness to travel distance, waiting times, and clinical quality using patient-level data for elective PTCA surgeries. We rely on the multinomial logit framework (McFadden, 1974), and model utility of patient $i$ conditional on choosing hospital $j$ at time $t$ as:

$U_{i j t}=V_{i j t}+v_{i j t}$

where $V_{i j t}$ is the deterministic component and $v_{i j t}$ is the random error term. Alternative assumptions on the error structure and on the coefficients lead to different model specifications. We estimate conditional logit (CL) and mixed logit (ML) models. In the $\mathrm{CL}$, the stochastic components of the conditional utility function in (1) are identically, independently distributed (iid) and follow a type-1 extreme value distribution. The deterministic component of utility is:

$V_{i j t}=\beta_{d i} f\left(D_{i j}\right)+\beta_{w i} W_{j t-1}+\beta_{q i} g\left(Q_{j t-1}\right)+\xi_{j}$

where $D_{i j}$ is the distance of patient $i$ from hospital $j, f$ is a cubic function of $D_{i j}, W_{j t-1}$ denotes the median waiting time for an elective PTCA at hospital $j$ in year $t-1, Q_{j t-1}$ is the quality at hospital $j$ in year $t-1$, and $g$ is a quadratic function of $Q_{j t-1} \cdot \xi_{j}$ is a vector of hospital-specific FEs. The vector of coefficients on distance, waiting times and quality of care $\left(\beta_{d i}, \beta_{w i}\right.$ and $\left.\beta_{q i}\right)$ are allowed to vary with patient characteristics 
so as to account for variation in preferences. Following previous studies, we assume that hospital choice responds to past, rather than current, waiting times and quality (e.g. Gutacker et al, 2016; Varkevisser et al, 2012). Lagged values prevent potential endogeneity due to the simultaneous influence of demand on waiting times and quality. Hospital FEs absorb differences in persistent hospital characteristics, including, among others, teaching status, size, or whether a hospital provides highly specialized services, reputation and experience effects. Hospital FEs are crucial for identifying the impact of waiting times, as they control for unobserved time-invariant hospital attributes possibly correlated with waiting times. The coefficient is identified by the relationship between waiting times and hospital choice within hospitals over time: a negative coefficient implies that, on average, hospitals whose waiting times increased between $t-1$ and $t$ decreased demand in period $t$, ceteris paribus.

The CL model relies on the Independence from Irrelevant Alternatives (IIA) property. Under this restrictive assumption, discrimination by patients among hospitals consists of pairwise comparisons unaffected by characteristics other than the pair under consideration. To overcome this limitation, we use the ML model, derived from the conditional utility function in (1) where $v_{i j t}$ are iid extreme values. The deterministic component of utility is the same as for the CL, except that the ML coefficients are allowed to vary randomly between individuals. By specifying individual random coefficients, the ML model accounts for unobserved preference heterogeneity and is robust to violations of the IIA (Train, 2009). 


\section{Data}

Our primary data source is the hospital discharge dataset (Schede di Dimissione Ospedaliera, SDO) that contains individual-level information for patients receiving NHS-funded care in Emilia-Romagna. We study intra-regional patient mobility for elective admissions. ${ }^{5}$ In doing so, we focus on short-distance movements of patients, while excluding long distance travels. Policy concerns for short-distance mobility largely prevail over those for the long-distance one, since the latter is relatively less frequent, in most cases involving highly complex procedures or idiosyncratic circumstances. On the contrary, the former can be induced by horizontal competition between nearby jurisdictions spurred by quality differences in local hospital markets: it involves larger groups of patients, with major implications for efficiency in resource allocation within the system, including the risk of unnecessary duplication of services. ${ }^{6}$

Our sample includes 15,766 patients undergoing elective PTCAs over the years 20082011, and each patient's choice set is assumed to embrace all publicly financed hospitals providing PTCAs. It comprises 22 hospitals in each year. On average, hospitals treat about 324 patients per year. The average number of patients treated by

\footnotetext{
${ }^{5} \mathrm{We}$ consider elective patients who reside in Emilia-Romagna. Non-elective (urgent) patients are excluded, as they are not placed on waiting lists. Residents treated in other regions are not included in our data, as these procedures are recorded in the datasets of destination regions. We also exclude residents from other regions treated in Emilia-Romagna, as their choice set should comprise the hospitals in the region of origin that do not appear in our dataset. Moreover, institutional barriers between regional health systems may affect the use of hospital services making the two groups of patients highly heterogeneous (Atella et al, 2014).

${ }^{6}$ The available evidence shows that inter-regional and intra-regional patient mobility in the Italian NHS are distinct phenomena influenced by different push and pull factors (e.g., Balia et al, 2020, 2018). Different determinants of patients' willingness-to-travel for care for short- and long-distance movements, as well as varying DRG tariffs between intra- and extra-regional patients, contribute to explain such findings.
} 
hospitals decreases from 344 to 266 between 2008 and $2011 .^{7}$ Figure 1 presents hospitals' location and volumes of activity.

[Figure 1 about here]

Waiting time is measured as the difference in number of days between the date when the patient is placed on the waiting list and the date of hospital admission. It has to be computed for each hospital in the choice set. However, while the waiting time at the chosen hospital is observed, the time a patient would have waited had he chosen an alternative provider is unknown. To tackle this problem, we follow Sivey (2012) in computing waiting times at the hospital-year level as the median of the individual waiting times for all elective PTCAs discharged at each hospital in each year. ${ }^{8}$

Clinical quality is measured by risk-adjusted mortality rates for AMI within 30 days of admission provided at hospital-year level by the Italian Ministry of Health through the National Outcome Evaluation Program (Programma Nazionale Esiti, PNE). The PNE releases procedure-specific indicators for all NHS hospitals for selected conditions and surgical interventions. These measures are computed linking clinical and administrative datasets, using rigorous scientific standards and validation procedures based on risk-adjustment mechanisms.

\footnotetext{
${ }^{7}$ Our model specification includes 22 alternative specific parameters corresponding to the regional hospitals that provide PTCAs, but no patient FEs. This feature ensures that, given our sample size, the estimator is free from the incidental parameter problem, which may affect non-linear models when the time dimension is short (s.c. small T) and the number of individual FEs increases with sample size (Lancaster, 2000).

${ }^{8}$ Median waits allow to account for the right skewed distribution of waiting times.
} 
The PNE indicators were not disclosed to the public during the observational period and, therefore, the choice of the hospital cannot be attributed to the patient's direct assessment of the performance indicator of reference. In our analysis, the PNE measure acts as a proxy for quality retrieved by patients from various sources, including GP and specialist advices, as well as previous personal experience and positive word-of-mouth (e.g. Moscone et al, 2012; Gutacker et al, 2016). Such broad quality dimension is influenced by the human and physical capital endowment of each hospital and by the effort to deliver effective treatments (Gaynor and Town, 2012). In turn, these features are assumed to influence performances measured by indicators issued by the PNE.

Empirical research pointed out the existence of statistically significant correlations between patients' overall rating of the hospital and measures based on technical quality (Castle et al, 2005; Isaac et al, 2010). As for the context of our study, patients' surveys conducted in Emilia-Romagna revealed that physicians' recommendations are one of the most important determinants of their hospital choice (Fiorentini et al, 1999) and indicators for technical quality, such as risk-adjusted mortality rates, can be effectively used as proxies of patients' perceptions on more general quality dimensions.

Travel distance is computed (in kilometres) using Microsoft MapPoint, as the fastest road line route from the centroid of the patient's municipality of residence to each hospital site. Patient characteristics include age, gender, foreign citizenship and the Charlson Comorbidity Index (CCI). To account for underserved areas, we add a dummy taking value 1 if there is only one hospital providing PTCAs in the patient's LHA of residence, and 0 otherwise. 
Since our dataset do not include individual-level proxies for socio-economic status, that has been shown to be relevant for hospital choice (e.g. Moscelli et al, 2018), we construct income-classes at the municipality level. Using data on average gross income from the Ministry of Economy and Finance, we construct dummy variables for each tertile of the income distribution, and attribute to each patient the income class corresponding to the municipality of residence.

Table 1 provides summary statistics. The average hospital has a median waiting time of 16 days and has risk-adjusted mortality rates equal to 9.9. Patients travel 18.6 kilometres on average for an elective PTCA, about three times the average distance to the nearest hospital, suggesting that choice is not uniquely driven by the purpose of minimising travel distance. Patients are on average 69 years old with a CCI of 1.028 , men prevail over women and foreigners are less than $2 \%$.

\section{Results}

Tables 2-3 present the results from the CL and the ML models, estimated using the clogit and mixlogit commands in Stata 16 (Hole, 2007a). The first three columns consider specifications where additional sets of regressors are successively included. The most parsimonious one (column 1) controls for distance and waiting times only, allowing for observed preference heterogeneity through interactions with patient characteristics. Then, we include hospital FEs (column 2). In our preferred specification as illustrated in equation (2), we add the risk-adjusted mortality rate (column 3). Lastly, we replicate the final specification without interactions to provide 
average estimates for the whole sample of patients (column 4). All models (1)-(4) also include squared and cubic distance terms and the squared term of AMI mortality accounting for non-linear effects of distance and quality. ${ }^{9}$

\subsection{Conditional logit estimates}

Since the related literature mainly exploits a CL specification, we report the corresponding estimates in Table 2 for comparability purposes.

[Table 2 about here]

However, such specification relies on the IIA hypothesis, which is not supported in our data according to the Hausmann-McFadden test. Hence, we refer to the discussion of the ML specification for more detailed comments (section 5.2). It is worth noticing here that distance has always a negative and significant effect, confirming that patients prefer closer hospitals, ceteris paribus. Our measure of clinical quality has a negative and statistically significant effect. The coefficient for waiting times is positive and significant before including any control for quality (column 1). It is no longer significant after accounting for time-invariant hospital differences through hospital FEs (column 2), while it becomes negative and significant once we control for clinical quality (column 3). Finally, the results of the ML without interactions (column 4) show

\footnotetext{
${ }^{9}$ We have also tested for non-linear effects of waiting times by adding the squared term. The results (available upon request) provide no evidence of non-linearities in the impact of waiting times on hospital choice. For this reason, the variable is entered in linear form.
} 
that the distance, waiting times and quality coefficients are qualitatively similar to those obtained with the full set of interactions (column 3).

\subsection{Mixed logit estimates}

Table 3 shows the ML estimates, where the distance coefficients are allowed to vary across patients. ${ }^{10}$ All remaining coefficients are assumed to be fixed as in the CL specification. ${ }^{11}$ We fit the ML model by maximum simulated likelihood using 50 Halton draws. ${ }^{12}$

[Table 3 about here]

Results are similar to those obtained from the CL model, with the log-likelihood statistics and the information criteria (AIC, BIC) indicating that the ML model fits the data better. Our preferred specification (column 3) shows that on average patients prefer closer hospitals, with shorter waiting times and lower mortality rates.

By comparing our findings across regressions (1)-(3), the coefficients are qualitatively similar except those for waiting times. While the effect of waiting times is positive and

\footnotetext{
${ }^{10}$ As pointed out by previous studies, unobserved preference heterogeneity for distance might reflect the influence exerted by patients' family or friends (network effects), which can reduce the welfare loss associated with travelling for care (Balia et al, 2020).

11 We have tested for the presence of unobserved heterogeneity with respect to waiting times and mortality rates. The results (available upon request) yield no evidence of significant unobserved heterogeneity with respect to neither waiting times or quality.

${ }^{12}$ We have tested the sensitivity of our findings in the final ML specification using up to 500 Halton draws. Even after increasing the number of draws by an order of ten, the estimated coefficients and the associated elasticities with respect to waiting times and quality are remarkably stable (results available upon request).
} 
significant before controlling for any dimension of hospital quality, it is no longer significant once we include hospital FEs, and becomes negative and significant after accounting for time-varying hospital quality. Such evidence suggests that omitting to control for either source of differences in quality would deliver biased estimates of waiting time elasticity.

The interactions between hospital attributes and patient characteristics point to preference heterogeneity associated to observable personal characteristics. On the whole, age differences across patients emerge as a key driver of preferences over hospital attributes. In line with prior research, older patients appear more reluctant to travel (e.g., Beckert et al, 2012; Gutacker et al, 2016). These individuals more frequently suffer from limited mobility which hinders their access to distant providers. We also find that older people are less sensitive to variations in hospital mortality rates, suggesting that they are less responsive to quality differences or have poorer access to information on quality. In addition, they show a greater dislike for longer waiting times. A higher marginal disutility of time spent on waiting lists for elective treatment is consistent with shorter life expectancy, but it may also reflect severe conditions other than those captured by the number of comorbidities that call for timely intervention. Sicker patients appear more willing to trade off distance and waiting times for quality: they are more prone to travel and to wait for care and more likely to choose high quality providers. In addition, patients living in areas with only one hospital performing PTCAs are less reluctant to travel, less willing to wait and more responsive to variations 
in clinical quality. Finally, patients residing in more income-deprived areas are more reluctant to travel and less sensitive to changes in waiting times and quality. ${ }^{13}$

\section{Size of the effect of waiting times and quality of care on hospital choice}

We estimate the elasticity of demand of hospital $j$ with respect to own waiting times as the $\%$ change in the predicted probability of choosing hospital $j$ associated with a $1 \%$ increase in own waiting times. To compute the predicted probabilities, we use the mixlpred command in Stata following our preferred ML specification based on Equation (2). We then calculate the mean of the $\%$ change in the predicted probabilities across all hospitals to provide the average $\%$ change in the expected demand (i.e., predicted number of patients) resulting from a $1 \%$ increase in own waiting times. Similarly, we derive the own quality demand elasticity of hospital $j$ as the $\%$ change in the predicted probability of choosing hospital $j$ associated with a $1 \%$ decrease in own mortality rates. ${ }^{14}$

Table 4 provides the means and standard deviations (SD) of the estimated demand elasticities. The results show a mean waiting time elasticity equal to -0.17 , suggesting that a $1 \%$ increase in average waiting times ( 0.16 days) leads to a decrease in the predicted number of admissions by around $0.17 \%$. With respect to own quality, the

\footnotetext{
${ }^{13}$ While our data on patients' socio-economic status are aggregated at municipality level, future research should also consider the use of patient-level information to more precisely assess the impact of patients' socio-economic status on their responsiveness to waiting times and quality.

${ }^{14}$ Unfortunately, this approach does not provide standard errors. While in principle the bootstrap procedure could be used as an alternative to obtain standard errors, it is usually not operational in practice due to the massive computational burden needed to estimate the ML model. Because of that, bootstrap procedures are typically not implemented following ML estimation.
} 
elasticity of demand is equal to -1.38 , so that a $1 \%$ increase in mortality rate $(10 \%$ of the sample average) reduces demand by around $1.4 \%$.

[Table 4 about here]

Further insights into how the estimated marginal utilities of distance, waiting times and quality vary with patient characteristics are provided in Table 5 . We use the delta method to provide standard errors (Hole, 2007b). The first column of Panel A displays the estimated marginal utilities obtained from the ML without interactions. The second column reports the marginal utilities derived from the ML with interactions for the reference patient, defined as the individual with average or modal characteristics (male, aged 69 years, Italian, with a CCI equal to 1.028, residing in the least income-deprived municipalities). In the successive columns we consider different "patient-types", whose characteristics varies each at a time, while keeping all other attributes at the level set for the reference patient. The exercise is performed for: females, patients at the 10th and 90th percentiles of the age and CCI distribution.

[Table 5 about here]

The most notable differences between the ML with and without interactions emerge for the quality attribute, with marginal utility varying largely across types of patients, whereas smaller differences are detected for the marginal utilities of distance and waiting times. Gender does not have a major impact on preferences, as women are only 
slightly less sensitive to variations in distance, waiting times and quality. On the contrary, age differences substantially affect sensitivity to quality, while leading to smaller changes in responsiveness to geographical proximity and waiting times. Patients at the 10th percentile of the age distribution (55 years) are less reluctant to travel and to wait for care compared to patients at the 90 th percentile ( 89 years) and are also considerably more sensitive to improvements in quality. As for severity, patients with a CCI score equal to 6 (90th decile) are keener to wait and to travel farther than the average patient and display a larger marginal utility of quality.

The marginal rates of substitution between hospital attributes provide further insights. Based on the coefficient estimates obtained in the ML without interactions, the first row and column of Panel B gives the ratio of the marginal utility of waiting times over the marginal utility of distance. Such ratio can be interpreted as WTT for shorter waiting times, the additional distance that on average patients would be willing to travel for a reduction in waiting times by 1 day. According to our estimates on average patients are willing to travel about 1.4 kilometres for a 1 -week reduction in waiting times. Similarly, the second row and first column of Panel B provides the WTT for higher quality. We find that on average patients are willing to travel about 0.12 kilometres for being treated in a hospital that ensures a 1\% reduction in AMI mortality. The remaining columns of Panel B illustrate the WTT based on the ML estimates with the full set of interactions. The results for the reference patient point to a higher WTT for a 1-week reduction in waiting times, equal to 2 kilometres, and a larger WTT for a $1 \%$ decrease in hospital mortality, equal to 0.8 kilometres. While individual differences in the trade-off between distance and waiting times are relatively small, the trade-off 
between distance and quality varies substantially across types of patients. Patients with more comorbidities appear more willing to travel farther for higher quality, a result that supports the assumption made in earlier studies (Gowrisankaran and Town, 1999) and that is in line with previous evidence finding that patients who are more severely ill care more about quality (Gaynor et al, 2006). Interestingly, younger patients are more willing to travel to seek higher quality care, other things equal, suggesting that they are more prone to screen hospital destinations and less influenced by the discouraging effect of distance.

Additionally, we examine the trade-off between waiting times and quality, referred to as WTW for better quality. In the first column of Panel $\mathrm{C}$, we show that on average patients are willing to wait about 0.6 days for a reduction in hospital mortality rate by $1 \%$. The results in columns (2)-(7) obtained in the ML with interactions reveal a large variation in WTW across patients, with the most willing to wait for higher quality being younger patients and those suffering from more severe conditions. For the reference patient, the results indicate a WTW of about 2.6 days for opting for a hospital where mortality decreases by $1 \%$.

\section{Robustness analyses}

\subsection{Restricted hospital choice sets}

Since patients can choose any publicly financed provider, in our main analysis we have defined the choice set to include all 22 regional hospitals providing PTCAs. However, patients may consider only the subset of alternatives that are geographically closer. To 
test the robustness of our findings, we present here ML estimates that apply more restrictive definitions of the choice set. Based on different conjectures about how patients process information, two approaches are typically employed: one relies on the hypothesis that patients focus on a given number of closest alternatives; the other assumes that patients consider only hospitals within a given distance radius.

As for the $k$-closest providers criterion, in line with previous studies, we restrict the potential destinations to the 10-closest hospitals (Howard, 2005; Sivey, 2012). Even though the choice set of each patient is more than halved, in our data the risk of disregarding relevant destinations is negligible, since $99 \%$ of the actual choices fall within such range. As for the fixed radius approach, Varkevisser et al (2014) consider 1-hour travel time as a critical range of reference. In our context, this roughly corresponds to a travel distance of $50 \mathrm{~km}$. Consistently, we redefine the patient choice sets to include all hospitals within a fixed radius distance of $50 \mathrm{~km}$. Such criterion comprises around $94 \%$ of the destinations actually chosen. ${ }^{15}$

In Table 6, we present the ML estimates using the 10-closest providers criterion, while Table 7 reports the estimates based on the $50 \mathrm{~km}$ radius. These findings can be directly compared to those of Table 3. For the sake of brevity, we do not show the coefficients for the full set of interactions and concentrate on waiting times, distance and quality measures.

\footnotetext{
15 The total number of observations used for the analysis is equal to 346,852 when we include all 22 alternatives, falls to 156,760 when applying the 10 closest providers criterion, and drops further to 75,855 with the fixed radius criterion.
} 
[Tables 6 and 7 about here]

The empirical findings are robust to alternative definitions of the patient choice set. As for waiting times, adding hospital fixed-effects and time-varying quality leads to a pattern similar to that recorded in Table 3. If we focus on the more general specification (model 3), also the magnitude of the waiting time coefficients is remarkably stable across different definitions of the choice set. The distance coefficient is smaller in size when considering hospitals within $50 \mathrm{~km}$ of distance from patient residence, suggesting that the discouraging effect of distance becomes relatively less important when more far-away hospitals are excluded from consideration.

\subsection{Extra-regional patient mobility}

Due to lack of individual information on patients travelling to other regions, our analysis considers intra-regional mobility only, and the parameters capture the drivers of short- and medium-distance patients' movements. However, some short distance movements may not be recorded in our data, as some individuals may choose hospitals just across the regional border. To assess the empirical relevance of the phenomenon, we exploit aggregate data for the set of DRGs that together count for $80 \%$ of all elective admissions included in our sample to identify the areas of the region characterised by non-negligible cross-border outflows. This information is available at the LHA-level only and suggests that cross border mobility occurs in particular from the LHAs of 
Piacenza and Parma. In most other cases, the share of patients treated outside the regional borders - including also long-distance movements - ranges between 3-5\%.

To test the robustness of our findings, we estimate our final ML specification excluding patients who reside in areas where outflows are non-negligible. In the remaining areas, we can confidently argue that the parameter estimates should not be affected by patients' outflows as the latter represent only a minor empirical issue. The results are reported in Table 8 .

[Table 8 about here]

We consider exclusion criteria based on administrative and geographical grounds. First, we exclude residents in the LHA of Piacenza alone, and then residents in the LHAs of Piacenza and Parma together (first and second column of Table 8, respectively). The geomorphic configuration of the region also suggests an alternative criterion based on the exclusion of municipalities located on the northern border of the region. EmiliaRomagna is characterised by high hills and mountains in the south-western part that is scarcely populated, with relatively poor transport infrastructures and limited mobility. On the contrary, the northern part is characterised by a flat territory, more densely populated and well connected through efficient transport networks. This points to the largest share of outflows being due to patients residing close to the northern border and being directed toward northern regions (Lombardy and Veneto), where the quality of health service is deemed to be as high as in Emilia-Romagna. Based on these considerations, we exclude patients residing in the municipalities located in the 
northern border of the region, irrespectively of the LHA they belong to (third column of Table 8). We find that restricting the analysis to geographical areas where patient outflows are a minor issue leaves the estimates largely unchanged. Such evidence is reassuring as it suggests that our main findings are not driven by missing information on residents treated in different regions.

\subsection{Additional indicators of hospital quality}

In our study, hospital quality acts as a magnet for patients' flows. Therefore, we are interested in proxies for quality broad enough to be credibly retrieved by patients through their sources of information (family networks, GPs, etc.), as well as in measures validated at the scientific and institutional level. The PNE program serves this purpose well: it is promoted by National and Regional Health Authorities and it releases risk-adjusted indicators for different clinical areas. We restrict our attention to the PNE indicators for the cardiological area. In our main analysis, we have used 30days AMI mortality rate as key time varying quality measure; an indicator that has gained a prominent position as a proxy for clinical quality of hospital services in general (e.g. Cooper et al, 2011; Bloom et al, 2015) and in the cardiological area in particular.

Yet, extending the spectrum of quality indicators may help account for features that a single measure may not capture. In this section, we assess the robustness of our findings by considering a richer set of measures for clinical quality. The additional indicators meet the following inclusion criteria: they refer to the cardiovascular area, are risk- 
adjusted and available for the full set of hospitals included in our sample. Among the measures released by the PNE, three additional indicators meet these minimum requirements: readmission rate after AMI, 30-day mortality rate for patients with heart failure and readmission rate for patients with heart failure. ${ }^{16}$ We report in Table 9 the estimates of our ML specification corresponding to column 3 of Table 3, augmented by the three quality indicators discussed above.

[Table 9 about here]

The results reported in Table 9 show that these additional measures for hospital quality do not seem to influence the probability that a patient chooses a particular destination once we control for differences in AMI mortality rate across providers, with the latter indicator emerging as a good summary measure for quality dimensions that are relevant for patient choice. Most importantly, our findings for the coefficients of main policy interest are largely unaffected.

\section{Discussion and conclusion}

As in Italy public hospital care is free of charge, patients trade off travel distance versus waiting times and clinical quality when choosing their destination for elective

\footnotetext{
${ }^{16}$ Ideally, it would have been advisable to include also quality indicators referring to elective procedures. Unfortunately, measures such as 30-day mortality rate for coronary bypass and for aortic valvuloplasty cannot be included in the present analysis. Due to the concentration of such procedures in a limited number of points of delivery, these indicators are released only for 6 out of the 22 hospitals of our sample.
} 
procedures. We estimated patient choice models to assess demand responsiveness to changes in waiting times and quality of care by using patient-level data on elective PTCA surgeries. A major challenge when studying mobility towards hospitals with shorter waiting times is the potential correlation with quality. Thanks to diseasespecific quality indicators issued by public authorities and to a balanced panel of hospitals, we are able to control for time-invariant quality (via the hospital FEs) and for the time varying aspects of clinical quality (via risk-adjusted mortality rates for AMI). In this way, we can relax assumptions that may not hold in every context, such as constant quality over time or uniform quality patterns within groups of hospitals, which were present in previous studies.

Our results documented the importance of jointly accounting for time-invariant differences across hospitals and time-varying clinical quality. Omitting time-varying quality controls produces biased estimates of responsiveness to waiting times, while no impact is recorded on the propensity to travel for care. We found that waiting times have a negative and significant impact on hospital demand, with the estimated average elasticity of demand for waiting times being -0.17 , and that on average patients are willing to travel an extra distance of about 1.4 kilometers for shortening waiting times for care by 1-week. There is relatively little variation in the trade-off between waiting times and distance across different types of patients, with the reference patient having a WTT for a 1-week reduction in waiting times equal to 2 kilometers. We also highlighted that patients respond to variations in hospital mortality rates over time, and estimated the average demand elasticity to mortality rates to be -1.38 . Responsiveness to changes in hospital quality varies widely across patient characteristics, with younger 
age groups and those more severely ill being more willing to trade off quality with distance and waiting times.

Waiting times have a negative and significant effect on demand. This has important implications for highly regulated healthcare systems. A relevant concern in such contexts is whether increasing NHS resources is an effective policy instrument to reduce waiting times. However, the interplay between demand- and supply-side factors in determining waiting times suggests that increasing public funding may not always result in a reduction in waiting times (e.g., Siciliani and Iversen, 2012), as increasing NHS capacity may bring forward previously latent demand. Small demand elasticity with respect to waiting times as shown in our study suggest that patients' response to a reduction in waiting time is relatively small on average. Net of this effect, increasing healthcare resources is expected to shorten waiting times.

Finally, our finding that hospital choice is affected by changes in clinical quality suggests that favouring well-informed patient choice - e.g., by disclosing information on hospital quality to the public - may produce beneficial effects also in highly regulated settings. We have shown that, even in such contexts, patients' sensitivity to quality changes makes hospitals with better health outcomes more attractive. At the same time, policy-makers should carefully monitor the consequences in terms of access to high quality care for those patients who are unlikely to bypass local providers. 


\section{Acknowledgements}

We are grateful for helpful comments received from Rinaldo Brau, Gianluca Fiorentini, Arne Risa Hole, Audrey Laporte, Giuseppe Moscelli, Carol Propper, Luigi Siciliani, and from participants at the AIES Conference, and the iHEA World Congress.

The research was funded by the Department of Health Policies of Emilia-Romagna (Italy) under the project "Revision of financing mechanisms for hospital care". We thank Eugenio Di Ruscio who coordinated the project for the Health Department. The views expressed are those of the authors and do not involve the funders in any respect. Any remaining errors are solely the authors' responsibility.

The study, based on routine administrative information, was carried out in compliance with Emilia-Romagna Regional Authority data processing regulations and the Italian Data Protection Act. Administrative data were anonymized prior to the analysis at the regional statistical office, where each patient is assigned a unique identifier. This identifier does not allow to trace the patient's identity and other sensitive information.

\section{References}

Aggarwal A., Lewis, D., Mason M., Sullivan R., van der Meulen J. 2017. Patient mobility for elective secondary health care services in response to patient choice policies: a systematic review. Medical Care Research and Review 74: 379-403.

Amaral-Garcia, S., Bertoli P., Grembi, V. 2015. Does experience rating improve obstetric practices? Evidence from Italy. Health Economics, 24, 1050-1064.

Atella V., Belotti F., Depalo D., Piano Mortari, A. 2014. Measuring spatial effects in the presence of institutional constraints: The case of Italian Local Health Authority expenditure. Regional Science and Urban Economics, 49, 232-241.

Avdic D., Moscelli G., Pilny A., Sriubaite, I. 2019. Subjective and objective quality and choice of hospital: Evidence from maternal care services in Germany. Journal of Health Economics, 68, 102229.

Balia S., Brau R., Marrocu E. 2014. What drives patient mobility across Italian regions? Evidence from hospital discharge data. In: Levaggi R., Montefiori M. (eds) Health Care Provision and Patient Mobility. Developments in Health Economics and Public Policy, vol 12. Springer.

Balia S., Brau R., Marrocu E. 2018. Interregional patient mobility in a decentralized healthcare system. Regional Studies 52, 388-402.

Balia S., Brau R., Moro D. 2020. Choice of hospital and long-distances: Evidence from Italy, Regional Science and Urban Economics, 81, 103502. 
Barili E., Bertoli P., Grembi V. 2021. Fee equalization and appropriate health care. Economics \& Human Biology 41, 100981.

Beckert W., Christensen M., Collyer K., 2012. Choice of NHS-funded hospital services in England. The Economic Journal 122: 400-417.

Berta P., Guerriero C. Levaggi R. 2021. Hospitals' strategic behaviours and patient mobility: Evidence from Italy, Socio-Economic Planning Sciences, forthcoming.

Berta P., Martini G., Moscone F., Vittadini G. 2016. The association between asymmetric information, hospital competition and quality of healthcare: evidence from Italy. Journal of the Royal Statistical Society Series A, 179: 907-926.

Bloom N. Propper C. Seiler S. Van Reenen J., 2015. The impact of competition on management quality: Evidence from public hospitals. Review of Economic Studies, 82, $457-489$.

Brekke, K., Gravelle, H., Siciliani, L., Straume, O., 2014. Patient choice, mobility and competition among health care providers. In: Levaggi R., Montefiori M. (eds) Health Care Provision and Patient Mobility. Developments in Health Economics and Public Policy, vol 12. Springer.

Cappellari, L., De Paoli, A., Turati G., 2016. Do market incentives for hospitals affect health and service utilization? Evidence from prospective pay system diagnosis-related groups tariffs in Italian regions. Journal of the Royal Statistical Society Series A, 179, 885-905.

Castle, N. G., Brown, J., Hepner, K. A., Hays, R. D., 2005. Review of the literature on survey instruments used to collect data on hospital patients' perceptions of care. Health Services Research, 40(6p2), 1996-2017.

Cookson, R., Dawson, D., 2012. Hospital competition and patient choice in publicly funded health care. In: Jones, A.M. (Eds.), Elgar Companion to Health Economics. Edward Elgar.

Cooper Z., Gibbons S., Jones S., McGuire A., 2011. Does hospital competition save lives? Evidence from the English NHS patient choice reforms. The Economic Journal, Volume 121, F228-F260.

Di Novi C., Piacenza M., Robone S., Turati G., 2019. Does fiscal decentralization affect regional disparities in health? Quasi-experimental evidence from Italy. Regional Science and Urban Economics, 78, 103465.

Fabbri D., Robone S. 2010. The geography of hospital admission in a national health service with patient choice. Health Economics, 19, 1029-1047. 
Fattore, G., Mariotti, G., Rebba, V., 2013. "Waiting times in Italy", in Siciliani, L., Borowitz, M., Moran, V. (eds.), Waiting-time Policies in the Health Sector: What Works?, OECD Publishing, Paris.

Ferré, F., de Belvis, A.G., Valerio, L., Longhi, S., Lazzari, A., Fattore, G., Ricciardi, W., Maresso, A., 2014. Health systems in transition, Italy. WHO on behalf of the European Observatory on Health Care Systems.

Fiorentini G., Ugolini C., Virgilio G., 1999. Processi decisionali nella domanda di prestazioni ospedaliere: un'analisi empirica, in D. Fabbri and G. Fiorentini (eds.) Domanda, mobilità sanitaria e programmazione dei servizi ospedalieri, Il Mulino, Italy: 113-152 (in Italian).

Gaynor M., Propper C., Seiler S., 2016. Free to choose? Reform, choice, and consideration sets in the English National Health Service. American Economic Review, 106: 3521-57.

Gowrisankaran, G., Town, R. J, 1999. Estimating the quality of care in hospitals using instrumental variables. Journal of Health Economics, 18, 747-767.

Gutacker, N., Siciliani, L., Moscelli, G., Gravelle, H., 2016. Choice of hospital: which type of quality matters? Journal of Health Economics 50: 230-246.

Gravelle, H., Santos R., Siciliani L. 2014. Does a hospital's quality depend on the quality of other hospitals? A spatial econometrics approach. Regional Science and Urban Economics, 49: 203-216.

Gravelle, H., Dusheiko, M., Sutton, M., 2002. The demand for elective surgery in a public system: Time and money prices in the UK National Health Service. Journal of Health Economics, 21: 423-449.

Gravelle, H., Smith, P., Xavier, A., 2003. Performance signals in the public sector: The case of health care. Oxford Economic Papers 55: 81-103.

Hodgkin, D., 1996. Specialized service offerings and patients' choice of hospital: The case of cardiac catheterization. Journal of Health Economics 15: 305-322.

Hole, A.R., 2007a. Fitting mixed logit models by using maximum simulated likelihood. The Stata Journal 7: 388-401.

Hole, A. R., 2007b. A comparison of approaches to estimating confidence intervals for willingness to pay measures. Health Economics, 16: 827-840.

Howard, D.H., 2005. Quality and consumer choice in healthcare: evidence from kidney transplantation. Topics in Economic Analysis and Policy 5: 24. 
Isaac, T., Zaslavsky, A. M., Cleary, P. D., Landon, B. E., 2010. The relationship between patients' perception of care and measures of hospital quality and safety. Health Services Research, 45, 1024-1040.

Lancaster, T., 2000. The incidental parameters problem since 1948. Journal of Econometrics, 95, 391-414.

Levaggi, R., Zanola R., 2004. Patients' migration across regions: the case of Italy, Applied Economics, 36, 1751-1757.

Lippi Bruni, M., Mammi, I., 2017. Spatial effects in hospital expenditures: a district level analysis, Health Economics, 26, 63 - 77.

Lippi Bruni, M., Mammi, I., Ugolini, C. 2016. Does the extension of primary care practice opening hours reduce the use of emergency services? Journal of Health Economics, 50, 144-155.

Martin, S., Smith, P.C., 1999. Rationing by waiting lists: An empirical investigation. Journal of Public Economics 71: 141-164.

Martin, S., Smith, P.C., 2003. Using panel methods to model waiting times for National Health Service surgery. Journal of the Royal Statistical Society Series A, 166: 369-387.

Martini, G., Berta, P., Mullahy, J., Vittadini G. 2014. The effectiveness-efficiency trade-off in health care: The case of hospitals in Lombardy, Italy. Regional Science and Urban Economics, Volume 49, 217-231.

McConnell K.J, Lindrooth, R.C., Wholey D.R., Maddox T.M., Bloom N., 2016. Modern management practices and hospital admissions. Health Economics 25: 470-85.

McFadden, D., 1974. Conditional logit analysis of qualitative choice behaviour. In: Zarembka, P. (Ed.), Frontier in Economics, vol. 4. Academic Press, New York, pp. 105-142.

Moscelli, G., Gravelle, H., Siciliani, L., Santos R. 2018, Heterogeneous effects of patient choice and hospital competition on mortality, Social Science and Medicine, 216: 50-58.

Moscelli, G., Siciliani, L., Gutacker, N., \& Cookson, R., 2018. Socioeconomic inequality of access to healthcare: Does choice explain the gradient?. Journal of Health Economics, 57, 290-314.

Moscelli, G., Siciliani, L., Gutacker, N., Gravelle, H., 2016. Location, quality and choice of hospital: Evidence from England 2002-2013. Regional Science and Urban Economics. 60: 112-124. 
Moscone, F., Tosetti, E., Vittadini, G., 2012. Social interaction in patients' hospital choice: evidence from Italy. Journal of the Royal Statistical Society Series A, 175: 453472.

Perucca, G., Piacenza, M., Turati, G. 2019. Spatial inequality in access to healthcare: evidence from an Italian Alpine region. Regional Studies, 53: 478-489.

Pope D.G., 2009. Reacting to rankings: Evidence from America's best hospitals. Journal of Health Economics 28: 1154-1165.

Riganti, A., Siciliani, L., Fiorio, C.V., 2017. The effect of waiting times on demand and supply for elective surgery: Evidence from Italy. Health Economics 26: 92-105.

Robertson, R., Burge1, P., 2011. The impact of patient choice of provider on equity: analysis of a patient survey. Journal of Health Services Research \& Policy, 16: 22-28.

Sivey, P., 2012. The effect of waiting time and distance on hospital choice for English cataract patients. Health Economics 21: 444-456.

Siciliani, L., Iversen, T., 2012. Waiting times and waiting lists. In A. M. Jones (ed.) The Elgar Companion to Health Economics (Second ed.) chapter 24.

Siciliani, L., Moran, V., Borowitz, M., 2014. Measuring and comparing health care waiting times in OECD countries. Health Policy 118: 292-303.

Tai, W. T. C., Porell, F. W., Adams, E. K., 2004. Hospital choice of rural Medicare beneficiaries: patient, hospital attributes, and the patient-physician relationship. Health Services Research, 39: 1903-1922.

Tay A., 2003. Assessing competition in hospital care markets: the importance of accounting for quality differentiation. Rand Journal of Economics, 34: 786-814.

Train, K.E., 2009. Discrete Choice Methods with Simulation, Cambridge University Press, Cambridge.

Varkevisser, M., van der Geest, S.A., 2007. Why do patients bypass the nearest hospital? An empirical analysis for orthopaedic care and neurosurgery in the Netherlands. The European Journal of Health Economics, 8: 287-295.

Varkevisser, M., van der Geest, S.A., Schut, F.T., 2012. Do patients choose hospitals with high quality ratings? Empirical evidence from the market for angioplasty in the Netherlands. Journal of Health Economics 31: 371-378.

Verzulli, R., Fiorentini, G., Lippi Bruni, M., Ugolini, C. 2017, Price changes in regulated healthcare markets: Do public hospitals respond and how? Health Economics, 26, 1429 - 1446. 
Figure 1. Emilia-Romagna region, map of hospital locations.

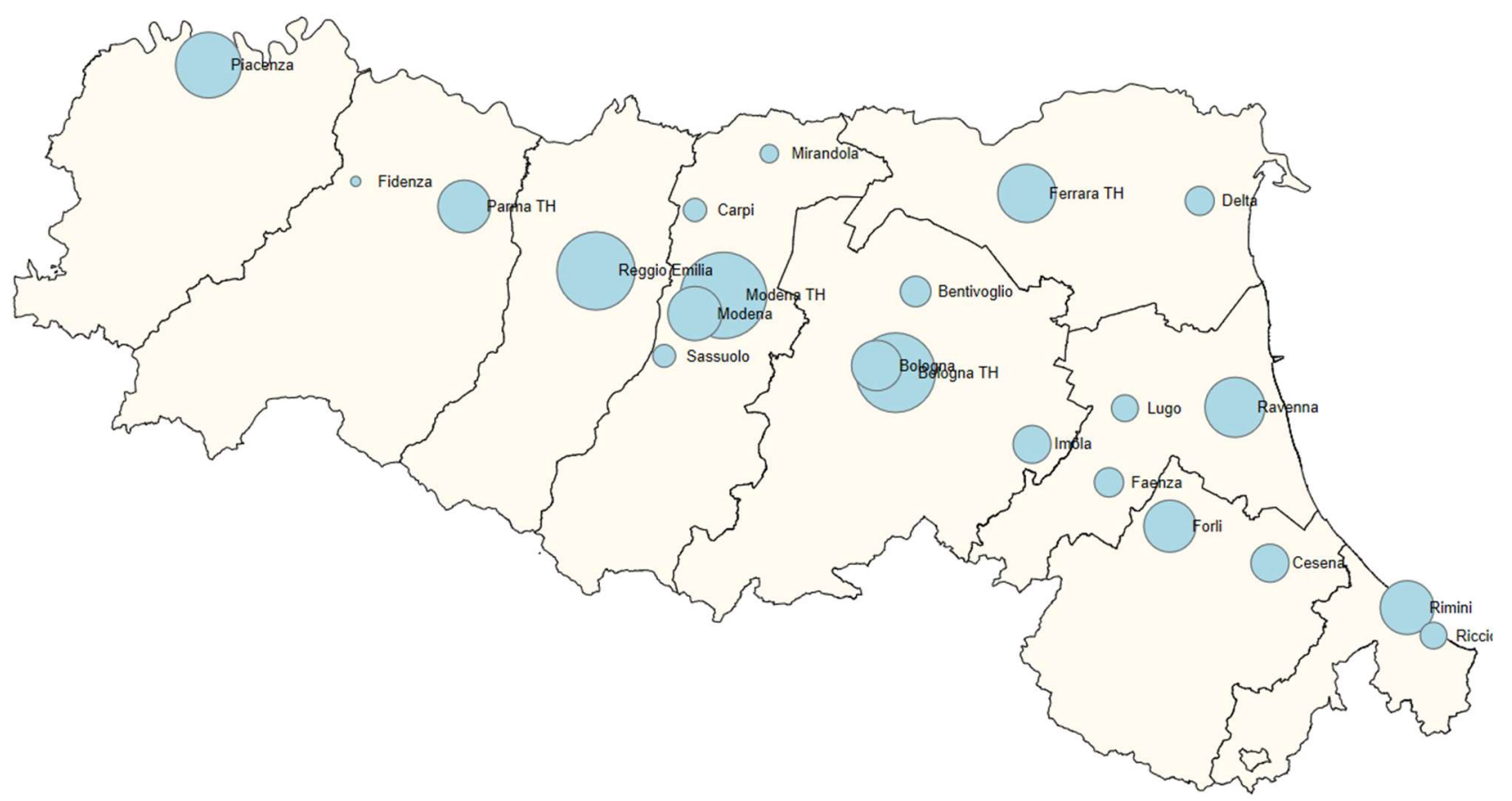

Note: Circle size is proportional to the volume of elective PTCA treatments provided in each hospital. $\mathrm{TH}$, teaching hospital. 
Table 1. Descriptive statistics: years 2008-2011.

\begin{tabular}{lcc}
\hline Variable & Mean & SD \\
\hline Hospital characteristics & & \\
Median annual inpatient waiting time (days) & 16.148 & 9.379 \\
Between-hospital variation & & 8.162 \\
Within-hospital variation & & 4.862 \\
AMI Mortality rate (\%) & 9.923 & 2.563 \\
Between-hospital variation & & 1.856 \\
Within-hospital variation & & 1.799 \\
Patient characteristics & & \\
Distance to hospital visited (km) & & \\
Distance to closest hospital (km) & 18.612 & 19.119 \\
Female & 6.457 & 6.436 \\
Age & 0.263 & 0.440 \\
Foreigner & 69.017 & 11.440 \\
Charlson comorbidity index (CCI) & 0.017 & 0.130 \\
Unique provider within the LHA of residence & 1.028 & 1.419 \\
Income deprivation - group 1 (more deprived) & 0.316 & 0.465 \\
Income deprivation - group 2 & 0.328 & 0.470 \\
Income deprivation - group 3 (least deprived) & 0.332 & 0.471 \\
& 0.339 & 0.473 \\
\hline
\end{tabular}

\section{Sample characteristics}

No. of hospitals

No. of patients

AMI, Acute Myocardial Infarction. LHA, Local Health Authority. SD, Standard Deviation. 
Table 2. Results from conditional logit estimation of hospital choice.

\begin{tabular}{|c|c|c|c|c|}
\hline Variable & Model 1 & Model 2 & Model 3 & Model 4 \\
\hline \multirow[t]{2}{*}{ Distance (in km) } & $-0.142 * * *$ & $-0.128 * * *$ & $-0.122 * * *$ & $-0.154 * * *$ \\
\hline & $(0.0113)$ & $(0.0132)$ & $(0.0132)$ & $(0.00262)$ \\
\hline \multirow[t]{2}{*}{ Distance $^{2}(/ 100)$} & $0.148 * * *$ & $0.159 * * *$ & $0.151 * * *$ & $0.0728 * * *$ \\
\hline & $(0.0182)$ & $(0.0212)$ & $(0.0212)$ & $(0.00413)$ \\
\hline \multirow[t]{2}{*}{ Distance $^{3}(/ 10000)$} & $-0.0456 * * *$ & $-0.0572 * * *$ & $-0.0543 * * *$ & $-0.0130 * * *$ \\
\hline & $(0.00759)$ & $(0.00921)$ & $(0.00919)$ & $(0.00164)$ \\
\hline \multirow[t]{2}{*}{ Waiting time } & $0.0464 * * *$ & 0.00323 & $-0.0274 * * *$ & $-0.0268 * * *$ \\
\hline & $(0.00748)$ & $(0.00975)$ & $(0.0106)$ & $(0.00293)$ \\
\hline \multirow[t]{2}{*}{ AMI mortality rate } & & & $0.535^{* *}$ & $0.311 * * *$ \\
\hline & & & $(0.238)$ & $(0.0538)$ \\
\hline \multirow[t]{2}{*}{ AMI mortality rate ${ }^{2}$} & & & $-0.0415 * * *$ & $-0.0166 * * *$ \\
\hline & & & $(0.0120)$ & $(0.00266)$ \\
\hline Interactions with distance & $\mathrm{Y}$ & $\mathrm{Y}$ & $\mathrm{Y}$ & $\mathrm{N}$ \\
\hline Interactions with distance ${ }^{2}$ & $\mathrm{Y}$ & $\mathrm{Y}$ & $\mathrm{Y}$ & $\mathrm{N}$ \\
\hline Interactions with distance ${ }^{3}$ & $\mathrm{Y}$ & $\mathrm{Y}$ & $\mathrm{Y}$ & $\mathrm{N}$ \\
\hline Interactions with waiting time & $\mathrm{Y}$ & $\mathrm{Y}$ & $\mathrm{Y}$ & $\mathrm{N}$ \\
\hline Interactions with AMI mortality & $\mathrm{N}$ & $\mathrm{N}$ & Y & $\mathrm{N}$ \\
\hline Interactions with AMI mortality rate ${ }^{2}$ & $\mathrm{~N}$ & $\mathrm{~N}$ & $\mathrm{Y}$ & $\mathrm{N}$ \\
\hline Hospital FEs & $\mathrm{N}$ & $\mathrm{Y}$ & Y & Y \\
\hline Log-likelihood & -16600.0 & -12503.7 & $-12,383.2$ & -12912.4 \\
\hline AIC & $33,264.0$ & $25,113.5$ & $24,904.4$ & 25878.7 \\
\hline $\mathrm{BIC}$ & $33,608.2$ & $25,683.6$ & $25,646.6$ & 26169.1 \\
\hline
\end{tabular}

AMI, Acute Myocardial Infarction.

Notes: Estimates from the conditional logit model. Years 2008-2011. All hospital-specific indicators are lagged by one year. No. of observations $=346,852$. No. of patients $=15,766$. No. of hospitals $=22$. Standard errors in parentheses. Significance levels: $* * * \mathrm{p}<0.01, * * \mathrm{p}<0.05,{ }^{*} \mathrm{p}<0.1$. 
Table 3. Results from mixed logit estimation of hospital choice.

\begin{tabular}{|c|c|c|c|c|}
\hline Variable & Model 1 & Model 2 & Model 3 & Model 4 \\
\hline \multirow[t]{2}{*}{ Distance (in km) } & $-0.154 * * *$ & $-0.132 * * *$ & $-0.126 * * *$ & $-0.164 * * *$ \\
\hline & $(0.0138)$ & $(0.0168)$ & $(0.0168)$ & (0.00338) \\
\hline \multirow[t]{2}{*}{ Distance $^{2}(/ 100)$} & $0.146^{* * *}$ & $0.125 * * *$ & $0.117 * * *$ & $0.0230 * * *$ \\
\hline & $(0.0242)$ & $(0.0290)$ & $(0.0292)$ & $(0.00717)$ \\
\hline \multirow[t]{2}{*}{ Distance $^{3}(/ 10000)$} & $-0.0640 * * *$ & $-0.0659 * * *$ & $-0.0625 * * *$ & $-0.0125^{* * *}$ \\
\hline & $(0.0111)$ & $(0.0130)$ & $(0.0132)$ & $(0.00321)$ \\
\hline \multirow[t]{2}{*}{ Waiting time } & $0.0520 * * *$ & 0.00795 & $-0.0241 * *$ & $-0.0312 * * *$ \\
\hline & $(0.00789)$ & $(0.0107)$ & $(0.0119)$ & (0.00323) \\
\hline \multirow[t]{2}{*}{ AMI mortality rate } & & & $0.458^{*}$ & $0.397 * * *$ \\
\hline & & & $(0.257)$ & $(0.0612)$ \\
\hline \multirow[t]{2}{*}{ AMI mortality rate ${ }^{2}$} & & & $-0.0380 * * *$ & $-0.0210 * * *$ \\
\hline & & & $(0.0129)$ & $(0.00301)$ \\
\hline \multicolumn{5}{|c|}{ Interactions with distance } \\
\hline \multirow[t]{2}{*}{ Age } & -0.0000281 & -0.000357 & -0.000371 & \\
\hline & $(0.000194)$ & $(0.000231)$ & $(0.000233)$ & \\
\hline \multirow[t]{2}{*}{ Female } & $0.0206^{* * *}$ & $0.0203 * * *$ & $0.0192 * * *$ & \\
\hline & $(0.00486)$ & $(0.00659)$ & $(0.00655)$ & \\
\hline \multirow[t]{2}{*}{ Foreigner } & -0.0123 & -0.0133 & -0.0161 & \\
\hline & $(0.0158)$ & $(0.0182)$ & $(0.0191)$ & \\
\hline \multirow[t]{2}{*}{$\mathrm{CCI}$} & $0.00598 * * *$ & $0.00596 * * *$ & $0.00611 * * *$ & \\
\hline & $(0.00145)$ & $(0.00199)$ & $(0.00197)$ & \\
\hline \multirow[t]{2}{*}{ Unique local provider } & $-0.0543 * * *$ & $-0.0229 * * *$ & $-0.0205 * * *$ & \\
\hline & $(0.00495)$ & $(0.00728)$ & $(0.00734)$ & \\
\hline \multirow[t]{2}{*}{ Income - 1 st tertile } & $0.0892 * * *$ & -0.00790 & -0.0123 & \\
\hline & $(0.00630)$ & $(0.00848)$ & $(0.00842)$ & \\
\hline \multirow[t]{2}{*}{ Income - 2nd tertile } & $0.0496^{* * *}$ & $-0.0307 * * *$ & $-0.0356 * * *$ & \\
\hline & $(0.00609)$ & $(0.00855)$ & $(0.00857)$ & \\
\hline \multicolumn{5}{|c|}{ Interactions with distance ${ }^{2}$} \\
\hline \multirow[t]{2}{*}{ Age } & $-0.00169 * * *$ & $-0.00164 * * *$ & $-0.00160 * * *$ & \\
\hline & $(0.000325)$ & $(0.000373)$ & $(0.000381)$ & \\
\hline \multirow[t]{2}{*}{ Female } & $-0.0156^{*}$ & -0.0106 & -0.00956 & \\
\hline & $(0.00809)$ & $(0.0116)$ & $(0.0115)$ & \\
\hline \multirow[t]{2}{*}{ Foreigner } & 0.000264 & -0.00234 & 0.00227 & \\
\hline & $(0.0252)$ & $(0.0277)$ & $(0.0300)$ & \\
\hline \multirow[t]{2}{*}{$\mathrm{CCI}$} & -0.00161 & 0.000191 & -0.0000952 & \\
\hline & (0.00233) & $(0.00346)$ & $(0.00340)$ & \\
\hline
\end{tabular}


Table 3. (continued).

\begin{tabular}{|c|c|c|c|c|}
\hline Variable & Model 1 & Model 2 & Model 3 & Model 4 \\
\hline \multirow[t]{2}{*}{ Unique local provider } & $0.0699 * * *$ & $0.0332 * * *$ & $0.0307 * * *$ & \\
\hline & $(0.00770)$ & $(0.0112)$ & $(0.0114)$ & \\
\hline \multirow[t]{2}{*}{ Income - 1 st tertile } & $-0.0867 * * *$ & 0.00815 & 0.0142 & \\
\hline & $(0.0109)$ & $(0.0139)$ & $(0.0137)$ & \\
\hline \multirow[t]{2}{*}{ Income - 2nd tertile } & $-0.0492 * * *$ & $0.0552 * * *$ & $0.0633 * * *$ & \\
\hline & $(0.0126)$ & $(0.0174)$ & $(0.0175)$ & \\
\hline \multicolumn{5}{|c|}{ Interactions with distance ${ }^{3}$} \\
\hline \multirow[t]{2}{*}{ Age } & $0.000761 * * *$ & $0.000845^{* * *}$ & $0.000824 * * *$ & \\
\hline & $(0.000142)$ & $(0.000163)$ & $(0.000169)$ & \\
\hline \multirow[t]{2}{*}{ Female } & 0.00360 & -0.000185 & -0.000444 & \\
\hline & $(0.00322)$ & $(0.00513)$ & $(0.00505)$ & \\
\hline \multirow[t]{2}{*}{ Foreigner } & 0.00713 & 0.0115 & 0.00964 & \\
\hline & $(0.00957)$ & $(0.0104)$ & $(0.0120)$ & \\
\hline \multirow[t]{2}{*}{ CCI } & -0.000495 & -0.00176 & -0.00160 & \\
\hline & $(0.000889)$ & $(0.00157)$ & $(0.00153)$ & \\
\hline \multirow[t]{2}{*}{ Unique local provider } & $-0.0206^{* * *}$ & $-0.00910 * *$ & $-0.00832 *$ & \\
\hline & $(0.00289)$ & $(0.00450)$ & $(0.00459)$ & \\
\hline \multirow[t]{2}{*}{ Income - 1 st tertile } & $0.0208 * * *$ & -0.00234 & -0.00433 & \\
\hline & $(0.00449)$ & $(0.00570)$ & $(0.00554)$ & \\
\hline \multirow[t]{2}{*}{ Income - 2nd tertile } & 0.00789 & $-0.0314 * * *$ & $-0.0348 * * *$ & \\
\hline & $(0.00605)$ & $(0.00892)$ & $(0.00903)$ & \\
\hline \multicolumn{5}{|c|}{ Interactions with waiting time } \\
\hline \multirow[t]{2}{*}{ Age } & $-0.000304 * * *$ & $-0.000689 * * *$ & $-0.000315^{* *}$ & \\
\hline & $(0.000110)$ & $(0.000146)$ & $(0.000161)$ & \\
\hline \multirow[t]{2}{*}{ Female } & $0.00548 *$ & $0.00978 * *$ & $0.0104 * *$ & \\
\hline & $(0.00301)$ & $(0.00401)$ & $(0.00444)$ & \\
\hline \multirow[t]{2}{*}{ Foreigner } & 0.000654 & -0.00769 & -0.0156 & \\
\hline & $(0.0108)$ & $(0.0142)$ & $(0.0156)$ & \\
\hline \multirow[t]{2}{*}{$\mathrm{CCI}$} & $0.00365 * * *$ & $0.00524 * * *$ & $0.00421 * * *$ & \\
\hline & $(0.000899)$ & $(0.00122)$ & $(0.00136)$ & \\
\hline \multirow[t]{2}{*}{ Unique local provider } & $-0.0794 * * *$ & $-0.0628 * * *$ & $-0.0445 * * *$ & \\
\hline & $(0.00344)$ & $(0.00534)$ & $(0.00586)$ & \\
\hline \multirow[t]{2}{*}{ Income - 1 st tertile } & $-0.00636^{*}$ & $0.0108 * *$ & $0.0172 * * *$ & \\
\hline & $(0.00355)$ & $(0.00502)$ & $(0.00563)$ & \\
\hline \multirow[t]{2}{*}{ Income - 2nd tertile } & $0.0153 * * *$ & $0.0116^{* *}$ & $0.0171 * * *$ & \\
\hline & $(0.00385)$ & $(0.00533)$ & $(0.00606)$ & \\
\hline
\end{tabular}


Table 3. (continued).

\begin{tabular}{|c|c|c|c|c|}
\hline Variable & Model 1 & Model 2 & Model 3 & Model 4 \\
\hline \multicolumn{5}{|c|}{ Interactions with AMI mortality } \\
\hline \multirow[t]{2}{*}{ Age } & & & -0.00361 & \\
\hline & & & $(0.00356)$ & \\
\hline \multirow[t]{2}{*}{ Female } & & & 0.0675 & \\
\hline & & & $(0.100)$ & \\
\hline \multirow[t]{2}{*}{ Foreigner } & & & 0.522 & \\
\hline & & & $(0.370)$ & \\
\hline \multirow[t]{2}{*}{ CCI } & & & $0.0887 * * *$ & \\
\hline & & & $(0.0322)$ & \\
\hline \multirow[t]{2}{*}{ Unique local provider } & & & $-0.637 * * *$ & \\
\hline & & & $(0.116)$ & \\
\hline \multirow[t]{2}{*}{ Income - 1 st tertile } & & & $0.422 * * *$ & \\
\hline & & & $(0.111)$ & \\
\hline \multirow[t]{2}{*}{ Income - 2nd tertile } & & & $0.303 * * *$ & \\
\hline & & & $(0.116)$ & \\
\hline \multicolumn{5}{|c|}{ Interactions with AMI mortality rate ${ }^{2}$} \\
\hline \multirow[t]{2}{*}{ Age } & & & $0.000319^{*}$ & \\
\hline & & & $(0.000179)$ & \\
\hline \multirow[t]{2}{*}{ Female } & & & -0.00282 & \\
\hline & & & $(0.00497)$ & \\
\hline \multirow[t]{2}{*}{ Foreigner } & & & -0.0297 & \\
\hline & & & $(0.0186)$ & \\
\hline \multirow[t]{2}{*}{$\mathrm{CCI}$} & & & $-0.00460 * * *$ & \\
\hline & & & $(0.00159)$ & \\
\hline \multirow[t]{2}{*}{ Unique local provider } & & & $0.0375 * * *$ & \\
\hline & & & $(0.00576)$ & \\
\hline \multirow[t]{2}{*}{ Income - 1 st tertile } & & & $-0.0180 * * *$ & \\
\hline & & & $(0.00553)$ & \\
\hline \multirow[t]{2}{*}{ Income - 2nd tertile } & & & $-0.0126^{* *}$ & \\
\hline & & & $(0.00579)$ & \\
\hline \multirow[t]{2}{*}{ SD of Distance } & & & $0.0536^{* * *}$ & $0.0601 * * *$ \\
\hline & & & $(0.00257)$ & $(0.00237)$ \\
\hline \multirow[t]{2}{*}{ SD of Distance ${ }^{2}$} & & & $0.00803 * * *$ & $-0.00732 * * *$ \\
\hline & & & $(0.00161)$ & $(0.00240)$ \\
\hline \multirow[t]{2}{*}{ SD of Distance ${ }^{3}$} & & & $-0.00198 * *$ & -0.000388 \\
\hline & & & $(0.000986)$ & $(0.000726)$ \\
\hline
\end{tabular}


Table 3. (continued).

\begin{tabular}{lcccc}
\hline Variable & Model 1 & Model 2 & Model 3 & Model 4 \\
\hline Hospital FEs & $\mathrm{N}$ & $\mathrm{Y}$ & $\mathrm{Y}$ & $\mathrm{Y}$ \\
Log-likelihood & $-16,443.0$ & $-12,290.8$ & $-12,179.4$ & $-12,533.0$ \\
AIC & $32,956.1$ & $24,693.6$ & $24,502.9$ & $25,126.1$ \\
BIC & $33,332.6$ & $25,296.0$ & $25,277.3$ & $25,448.8$ \\
\hline
\end{tabular}

AMI, Acute Myocardial Infarction.

Notes: Estimates obtained using the Stata mixlogit command (Hole, 2007a), 50 Halton draws. Years 2008-2011. All hospital specific indicators are lagged by one year. No. of observations $=346,852$. No. of patients $=15,766$. No. of hospitals $=22$. Standard errors in italics. Significance levels: $* * *_{p}<0.01, * * \mathrm{p}<0.05, * \mathrm{p}<0.1$. 
Table 4. Average elasticities of demand.

Average elasticity of demand

Waiting time (days)

$-0.17$

(0.139)

Mortality rate from AMI (\%)

$-1.38$

(1.292)

AMI, acute myocardial infarction.

Notes: Results based on the mixed logit regression in column 3 of Table 3. Standard deviations in parentheses.

Table 5. Marginal utility, WTT and WTW: main effects and effect by type of patient.

\begin{tabular}{|c|c|c|c|c|c|c|c|}
\hline & \multirow{2}{*}{$\begin{array}{c}\text { Mixed logit } \\
\text { without } \\
\text { interactions }\end{array}$} & \multicolumn{6}{|c|}{ Mixed logit with interactions } \\
\hline & & Baseline & Female & Age $=55$ & Age $=89$ & $\mathbf{C C I}=\mathbf{0}$ & $\mathrm{CCI}=6$ \\
\hline \multicolumn{8}{|l|}{ Panel A: Marginal utility } \\
\hline \multirow[t]{2}{*}{ Distance (in km) } & $-0.157 * *$ & $-0.144^{* * *}$ & $-0.128^{* * *}$ & $-0.131 * * *$ & $-0.161 * * *$ & $-0.150 * * *$ & $-0.114^{* * *}$ \\
\hline & $(0.002)$ & $(0.004)$ & $(0.004)$ & $(0.004)$ & $(0.005)$ & $(0.004)$ & $(0.006)$ \\
\hline \multirow[t]{2}{*}{ Waiting time (days) } & $-0.031 * * *$ & $-0.042 * * *$ & $-0.031 * * *$ & $-0.037 * * *$ & $-0.048 * * *$ & $-0.046^{* * *}$ & $-0.021 * *$ \\
\hline & $(0.003)$ & $(0.005)$ & $(0.006)$ & $(0.006)$ & $(0.006)$ & $(0.005)$ & $(0.008)$ \\
\hline \multirow[t]{2}{*}{ Mortality rate from AMI (\%) } & $-0.019^{*}$ & $-0.110^{* * *}$ & $-0.098 * * *$ & $-0.148 * * *$ & $-0.055^{* * *}$ & $-0.107 * * *$ & $-0.122 * * *$ \\
\hline & $(0.010)$ & $(0.017)$ & $(0.020)$ & $(0.019)$ & $(0.021)$ & $(0.018)$ & $(0.029)$ \\
\hline \multicolumn{8}{|l|}{ Panel B: WTT } \\
\hline \multirow[t]{2}{*}{ Waiting time (days) } & $0.197 * * *$ & $0.292 * * *$ & $0.242 * * *$ & $0.282 * * *$ & $0.298 * * *$ & $0.306^{* * *}$ & $0.184^{* *}$ \\
\hline & $(0.021)$ & $(0.037)$ & $(0.048)$ & $(0.044)$ & $(0.040)$ & $(0.037)$ & $(0.075)$ \\
\hline \multirow[t]{2}{*}{ Mortality rate from AMI (\%) } & $0.121^{*}$ & $0.764 * * *$ & $0.766^{* * *}$ & $1.129 * * *$ & $0.342 * * *$ & $0.713 * * *$ & $1.070 * * *$ \\
\hline & $(0.066)$ & $(0.123)$ & $(0.160)$ & $(0.147)$ & $(0.130)$ & $(0.122)$ & $(0.264)$ \\
\hline \multicolumn{8}{|l|}{ Panel C: WTW } \\
\hline \multirow[t]{2}{*}{ Mortality rate from AMI (\%) } & $0.613^{*}$ & $2.619^{* * *}$ & $3.161 * * *$ & $4.000^{* * *}$ & $1.146^{* * *}$ & $2.326^{* * *}$ & $5.810^{* *}$ \\
\hline & $(0.330)$ & $(0.455)$ & $(0.737)$ & $(0.660)$ & $(0.414)$ & $(0.413)$ & $(2.344)$ \\
\hline
\end{tabular}

AMI, acute myocardial infarction. WTT, willingness to travel. WTW, willingness to wait.

Notes: ML without interactions: results based on the mixed logit regression in column 4 of Table 3. ML with interactions: results based on the mixed logit regression in column 3 of Table 3. Standard errors calculated using the delta method are reported in parentheses. 
Table 6. Mixed logit model: choice set with the 10 nearest hospitals.

\begin{tabular}{|c|c|c|c|c|}
\hline Variable & Model 1 & Model 2 & Model 3 & Model 4 \\
\hline \multirow[t]{2}{*}{ Distance (in km) } & $-0.156^{* * *}$ & $-0.167 * * *$ & $-0.164 * * *$ & $-0.166^{* * *}$ \\
\hline & $(0.0212)$ & $(0.0258)$ & $(0.0260)$ & $(0.00471)$ \\
\hline \multirow[t]{2}{*}{ Distance $^{2}(/ 100)$} & $0.102 *$ & $0.160 * * *$ & $0.179 * * *$ & $0.0291 * * *$ \\
\hline & $(0.0533)$ & $(0.0592)$ & $(0.0609)$ & $(0.0112)$ \\
\hline \multirow[t]{2}{*}{ Distance $^{3}(/ 10000)$} & 0.00773 & -0.0550 & $-0.0761 * *$ & $-0.0275^{* *}$ \\
\hline & $(0.0356)$ & $(0.0365)$ & $(0.0384)$ & $(0.0114)$ \\
\hline \multirow[t]{2}{*}{ Waiting time } & $0.0467 * * *$ & -0.00575 & $-0.0356 * * *$ & $-0.0314 * * *$ \\
\hline & $(0.00831)$ & $(0.0115)$ & $(0.0126)$ & $(0.00327)$ \\
\hline \multirow[t]{2}{*}{ AMI mortality rate } & & & $0.473 *$ & $0.415^{* * *}$ \\
\hline & & & $(0.266)$ & $(0.0618)$ \\
\hline \multirow[t]{2}{*}{ AMI mortality rate ${ }^{2}$} & & & $-0.0380 * * *$ & $-0.0220 * * *$ \\
\hline & & & $(0.0134)$ & $(0.00305)$ \\
\hline Interactions with distance & $\mathrm{Y}$ & $\mathrm{Y}$ & $\mathrm{Y}$ & $\mathrm{N}$ \\
\hline Interactions with distance ${ }^{2}$ & Y & $\mathrm{Y}$ & $\mathrm{Y}$ & $\mathrm{N}$ \\
\hline Interactions with distance ${ }^{3}$ & Y & $\mathrm{Y}$ & Y & $\mathrm{N}$ \\
\hline Interactions with waiting time & $\mathrm{Y}$ & $\mathrm{Y}$ & $\mathrm{Y}$ & $\mathrm{N}$ \\
\hline Interactions with AMI mortality & $\mathrm{N}$ & $\mathrm{N}$ & $\mathrm{Y}$ & $\mathrm{N}$ \\
\hline Interactions with AMI mortality rate ${ }^{2}$ & $\mathrm{~N}$ & $\mathrm{~N}$ & $\mathrm{Y}$ & $\mathrm{N}$ \\
\hline \multirow[t]{2}{*}{ SD of Distance } & $0.0240 * * *$ & $0.0535 * * *$ & $-0.0432 * * *$ & $0.0543 * * *$ \\
\hline & $(0.00498)$ & $(0.00281)$ & $(0.00311)$ & $(0.00364)$ \\
\hline \multirow[t]{2}{*}{ SD of Distance ${ }^{2}$} & $0.0424 * * *$ & 0.0104 & $0.0374 * * *$ & $0.0371 * * *$ \\
\hline & $(0.00468)$ & $(0.00668)$ & $(0.00387)$ & $(0.00775)$ \\
\hline \multirow[t]{2}{*}{ SD of Distance ${ }^{3}$} & $-0.00691^{*}$ & -0.00063 & $0.00650 * * *$ & $-0.00883^{* *}$ \\
\hline & $(0.00381)$ & $(0.00233)$ & $(0.00231)$ & $(0.00388)$ \\
\hline Hospital FEs & $\mathrm{N}$ & $\mathrm{Y}$ & $\mathrm{Y}$ & $\mathrm{Y}$ \\
\hline Log-likelihood & -15564 & -11526.1 & $-11,404.4$ & -11768.5 \\
\hline $\mathrm{AIC}$ & 31198.1 & 23164.2 & $22,952.7$ & 23597 \\
\hline $\mathrm{BIC}$ & 31546.8 & 23722.1 & $23,670.0$ & 23895.9 \\
\hline
\end{tabular}

AMI, Acute Myocardial Infarction.

Notes: Estimates obtained using Stata mixlogit command (Hole, 2007a), 50 Halton draws. All hospital-specific indicators are lagged by one year. No. of observations $=156,760$. No. of patients $=15,676$. No. of hospitals $=10$. Standard errors are in parentheses. Significance levels: $* * * \mathrm{p}<0.01,{ }^{*} \mathrm{p}<0.05,{ }^{*} \mathrm{p}<0.1$. 
Table 7. Mixed logit model: choice set with all hospitals within $50 \mathrm{~km}$ from patient residence.

\begin{tabular}{|c|c|c|c|c|}
\hline Variable & Model 1 & Model 2 & Model 3 & Model 4 \\
\hline \multirow[t]{2}{*}{ Distance (in km) } & $-0.121 * * *$ & $-0.125^{* * *}$ & $-0.122 * * *$ & $-0.160 * * *$ \\
\hline & $(0.0251)$ & $(0.0344)$ & $(0.0340)$ & $(0.00529)$ \\
\hline \multirow[t]{2}{*}{ Distance $^{2}(/ 100)$} & -0.0308 & -0.0249 & -0.0147 & $0.0221 * *$ \\
\hline & $(0.0540)$ & $(0.0718)$ & $(0.0710)$ & $(0.0110)$ \\
\hline \multirow[t]{2}{*}{ Waiting time } & $0.0410 * * *$ & -0.0154 & $-0.0408 * * *$ & $-0.0315^{* * *}$ \\
\hline & $(0.00965)$ & $(0.0135)$ & $(0.0147)$ & $(0.00337)$ \\
\hline \multirow[t]{2}{*}{ AMI mortality rate } & & & 0.408 & $0.404 * * *$ \\
\hline & & & $(0.298)$ & $(0.0634)$ \\
\hline \multirow[t]{2}{*}{ AMI mortality rate ${ }^{2}$} & & & $-0.0332 * *$ & $-0.0214 * * *$ \\
\hline & & & $(0.0150)$ & $(0.00314)$ \\
\hline Interactions with distance & $\mathrm{Y}$ & $\mathrm{Y}$ & $\mathrm{Y}$ & $\mathrm{N}$ \\
\hline Interactions with distance ${ }^{2}$ & $\mathrm{Y}$ & Y & Y & $\mathrm{N}$ \\
\hline Interactions with waiting time & $\mathrm{Y}$ & $\mathrm{Y}$ & $\mathrm{Y}$ & $\mathrm{N}$ \\
\hline Interactions with AMI mortality & $\mathrm{N}$ & $\mathrm{N}$ & $\mathrm{Y}$ & $\mathrm{N}$ \\
\hline Interactions with AMI mortality rate ${ }^{2}$ & $\mathrm{~N}$ & $\mathrm{~N}$ & $\mathrm{Y}$ & $\mathrm{N}$ \\
\hline \multirow[t]{2}{*}{ SD of Distance } & -0.0151 & $0.0443 * * *$ & $0.0438 * * *$ & $0.0402 * * *$ \\
\hline & (0.00946) & $(0.00418)$ & $(0.00425)$ & $(0.00381)$ \\
\hline \multirow[t]{2}{*}{ SD of Distance ${ }^{2}$} & -0.00644 & 0.00126 & 0.000401 & 0.00270 \\
\hline & $(0.0223)$ & $(0.0126)$ & $(0.0127)$ & $(0.0146)$ \\
\hline Hospital FEs & $\mathrm{N}$ & Y & Y & Y \\
\hline Log-likelihood & -12510.9 & -8978.3 & $-8,876.6$ & -9090.8 \\
\hline AIC & 25073.8 & 18050.6 & $17,879.3$ & 18237.7 \\
\hline $\mathrm{BIC}$ & 25313.9 & 18484.7 & $18,461.2$ & 18496.3 \\
\hline
\end{tabular}

AMI, Acute Myocardial Infarction.

Notes: Estimates obtained using Stata mixlogit command (Hole, 2007a), 50 Halton draws. All hospital-specific indicators are lagged by one year. No. of observations $=75,855$. No. of patients $=14,794$. No. of hospitals $=22$. Standard errors are in parentheses. Significance levels: $* * * p<0.01, * * p<0.05, * p<0.1$. 
Table 8. Mixed logit model: sensitivity analyses using different sample sets.

\begin{tabular}{|c|c|c|c|}
\hline Variable & (1) & (2) & (3) \\
\hline \multirow[t]{2}{*}{ Distance (in km) } & $-0.117 * * *$ & $-0.119 * * *$ & $-0.107 * * *$ \\
\hline & $(0.0172)$ & $(0.0190)$ & $(0.0162)$ \\
\hline \multirow[t]{2}{*}{ Distance $^{2}(/ 100)$} & $0.086 * * *$ & $0.0891 * *$ & $0.0728 * * *$ \\
\hline & $(0.0298)$ & $(0.0349)$ & $(0.0271)$ \\
\hline \multirow[t]{2}{*}{$\operatorname{Distance}^{3}(/ 10000)$} & $-0.044 * * *$ & $-0.0473 * * *$ & $-0.0404 * * *$ \\
\hline & $(0.0132)$ & $(0.0167)$ & $(0.0116)$ \\
\hline \multirow[t]{2}{*}{ Waiting time } & $-0.0274 * *$ & $-0.0269 * *$ & $-0.0209 *$ \\
\hline & $(0.0121)$ & $(0.0128)$ & $(0.0121)$ \\
\hline \multirow[t]{2}{*}{ AMI mortality rate } & $0.4982 *$ & $0.487^{*}$ & $0.558 * *$ \\
\hline & $(0.2599)$ & $(0.262)$ & $(0.265)$ \\
\hline \multirow[t]{2}{*}{ AMI mortality rate ${ }^{2}$} & $-0.0404 * * *$ & $-0.0399 * * *$ & $-0.0428 * * *$ \\
\hline & $(0.0131)$ & $(0.0132)$ & $(0.0133)$ \\
\hline Interactions with distance & $\mathrm{Y}$ & Y & Y \\
\hline Interactions with distance ${ }^{2}$ & Y & $\mathrm{Y}$ & Y \\
\hline Interactions with distance ${ }^{3}$ & Y & $\mathrm{Y}$ & $\mathrm{Y}$ \\
\hline Interactions with waiting time & $\mathrm{Y}$ & Y & $\mathrm{Y}$ \\
\hline Interactions with AMI mortality & Y & $\mathrm{Y}$ & $\mathrm{Y}$ \\
\hline Interactions with AMI mortality rate ${ }^{2}$ & Y & $\mathrm{Y}$ & Y \\
\hline \multirow[t]{2}{*}{ SD of distance } & $0.056 * * *$ & $0.0580 * * *$ & $0.0550 * * *$ \\
\hline & $(0.0026)$ & $(0.00288)$ & $(0.00286)$ \\
\hline \multirow[t]{2}{*}{ SD of distance 2} & -0.002 & -0.000811 & -0.000142 \\
\hline & $(0.0019)$ & $(0.00227)$ & $(0.00172)$ \\
\hline \multirow[t]{2}{*}{ SD of distance 3} & 0.0003 & -0.000175 & 0.000243 \\
\hline & $(0.0009)$ & $(0.00135)$ & $(0.000722)$ \\
\hline Hospital FEs & Y & $\mathrm{Y}$ & Y \\
\hline Log-likelihood & $-11,886.6$ & -11428.1 & -11516.9 \\
\hline $\mathrm{AIC}$ & $23,917.2$ & 23000.2 & 23177.9 \\
\hline $\mathrm{BIC}$ & $24,685.6$ & 23764.2 & 23946.4 \\
\hline No. of observations & 318,560 & 299,882 & 319,066 \\
\hline No. of patients & 14,480 & 13,631 & 14,503 \\
\hline
\end{tabular}

AMI, Acute Myocardial Infarction.

Notes: Results based on the mixed logit regression in column 3 of Table 3 using different sample sets: (1) - sample excludes residents in the LHA of Piacenza; (2) - sample excludes residents in the LHAs of Piacenza and Parma; (3) sample excludes residents in the Emilia-Romagna's northern border. All hospital-specific indicators are lagged by one year. Standard errors in parentheses. No. of hospitals $=22$. Significance levels: ${ }^{* * *} \mathrm{p}<0.01,{ }^{* *} \mathrm{p}<0.05,{ }^{*} \mathrm{p}<0.1$. 
Table 9. Mixed logit model: sensitivity analysis to the inclusion of other quality indicators

\begin{tabular}{lc}
\hline Variable & Coeff. \\
\hline Distance (in km) & $-0.110^{* * *}$ \\
& $(0.0166)$ \\
Distance $^{2}(/ 100)$ & $0.0816^{* * *}$ \\
& $(0.0281)$ \\
Distance $^{3}(/ 10000)$ & $-0.0461^{* * *}$ \\
& $(0.0121)$ \\
Waiting time & $-0.0316^{* *}$ \\
& $(0.0124)$ \\
AMI mortality rate & $0.553^{* *}$ \\
& $(0.262)$ \\
AMI mortality rate & \\
& $-0.0426^{* * *}$ \\
AMI readmission rate & $(0.0132)$ \\
& 0.00813 \\
Heart failure mortality rate & $(0.0182)$ \\
& -0.0260 \\
Heart failure readmission rate & $(0.0362)$ \\
& 0.0673 \\
Interactions with distance & $(0.0426)$ \\
Interactions with distance & $\mathrm{Y}$ \\
Interactions with distance & \\
Interactions with waiting time & $\mathrm{Y}$ \\
Interactions with AMI mortality & $\mathrm{Y}$ \\
Interactions with AMI mortality rate & 2 \\
Interactions with AMI readmission rate & $\mathrm{Y}$ \\
Interactions with heart failure mortality rate & $\mathrm{Y}$ \\
Interactions with heart failure readmission rate & $\mathrm{Y}$ \\
SD of Distance & $-0.0540^{* * *}$ \\
& $(0.00263)$ \\
& 0.00116 \\
& $(0.00207)$ \\
& $0.00106^{*}$ \\
& $(0.000585)$ \\
\hline
\end{tabular}

AMI, Acute Myocardial Infarction.

Notes: Estimates obtained using the Stata mixlogit command (Hole, 2007a), 50 Halton draws. Years 2008-2011. All hospital specific indicators are lagged by one year. No. of observations $=341,471$. No. of patients $=15,766$. No. of hospitals $=22$. Standard errors in italics. Significance levels: $* * * p<0.01, * * p<0.05, * \mathrm{p}<0.1$. 


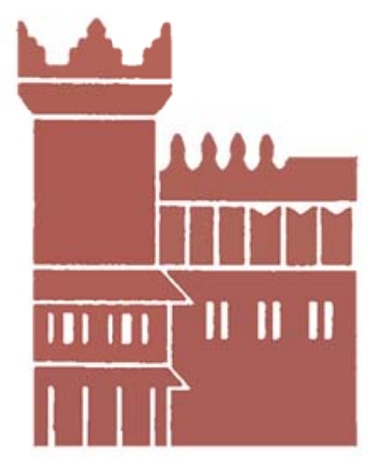

Alma Mater Studiorum - Università di Bologna DEPARTMENT OF ECONOMICS

Strada Maggiore 45

40125 Bologna - Italy

Tel. +39051 2092604

Fax +390512092664

http://www.dse.unibo.it 